\title{
Parts of the Whole: Only Connect
}

\section{Dorothy Wallace}

Dartmouth College, dorothy.wallace@dartmouth.edu

Follow this and additional works at: https://digitalcommons.usf.edu/numeracy

Part of the Educational Leadership Commons, Higher Education Commons, Other Social and Behavioral Sciences Commons, and the Science and Mathematics Education Commons

\section{Recommended Citation}

Wallace, Dorothy. "Parts of the Whole: Only Connect." Numeracy 7, Iss. 1 (2014): Article 9. DOI: http://dx.doi.org/10.5038/1936-4660.7.1.9 


\title{
Parts of the Whole: Only Connect
}

\begin{abstract}
This is the first of several columns that will focus on the mechanisms by which new ideas become accepted by a culture, offering some familiar examples, deriving basic principles from these examples, and applying them to the problem of promoting quantitative literacy in an educational system. In this essay we describe how new concepts become embedded in a culture through their connections to existing ideas, and use this principle to suggest strategies of discourse about numeracy that promote it among various constituencies in the culture.
\end{abstract}

\section{Keywords}

education reform, memetics, quantitative literacy, quantitative reasoning, numeracy

Creative Commons License

(c) (i) (8)

This work is licensed under a Creative Commons Attribution-Noncommercial 4.0 License

\section{Cover Page Footnote}

Dorothy Wallace is a professor of mathematics at Dartmouth. She was 2000 New Hampshire CASE Professor of the Year, and the lead PI of the seminal NSF project, Mathematics Across the Curriculum. She recently finished a text in mathematical biology for first-year students, "Situated Complexity." She was a charter board member of the National Numeracy Network and is now co-editor of this journal.

This column is available in Numeracy: https://digitalcommons.usf.edu/numeracy/vol7/iss1/art9 


\section{Parts Of The Whole A Column by $\mathrm{D}$. Wallace}

The problem of how best to improve the numeracy of a society is a thorny one, embracing the learning process of a single student but rising in scale to include the management and alteration of an entire system of education. With the issue of quantitative literacy always in mind, this column will consider various aspects of the systemic workings of education, the forces acting on classrooms, teachers and students, and mechanisms of both stasis and change.

\section{Only Connect}

One way to think of numeracy is as the habit of mind that allows us to use whatever mathematical understanding we may have acquired in the service of estimating and predicting quantities in the world around us. Scientists and engineers use such skills as a matter of course, but it is a relatively new thought that every educated person ought to be in the habit of using their mathematical skills routinely to improve their understanding of their own world. As a relatively new thought, the concept of numeracy struggles to take its place in the educational system, which is already densely packed with standards, required curricula, prerequisites, and distributional requirements (usually) based on other concepts that people find compelling and important.

Advocates of numeracy know that most of these competing interests will actually be easier to implement in a population of quantitatively literate individuals. They see quantitative issues everywhere. Early articles on the subject were full of reasoned yet passionate argument supporting a nearly irrefutable need for such education. And yet the demand that high school or college graduates (to take an example) display a basic level of numeracy is still heard as a relatively faint voice. Thus, as part of our considerations of how the educational system works, we should also consider how new ideas take hold in a culture or community, because we have an idea we would like to see grow in importance. In the next few columns in this series I would like to focus on the mechanisms by which new ideas become accepted by a culture, offering some familiar examples, inferring basic principles from these examples, and applying them to the problem of promoting quantitative literacy in our culture.

\section{Memetics 101}

It is useful to look at the world of ideas through a lens borrowed from the study of biological processes of ecology and evolution. An early approach was developed 
by psychologist Gregory Bateson ${ }^{1}$ when the science of ecology was still quite young. Here Bateson likens the workings of an individual cognition to an ecological system. Later, biologist Richard Dawkins ${ }^{2}$ coined the term "meme" to describe the idea equivalent of a gene and likened the spread of a new idea throughout a population to infection by a virus. Since the time Dawkins made this analogy, the study of ecology, epidemiology and evolution using mathematical techniques has come pretty far along and models for the spread of ideas can be postulated and tested on the computer to see what the model predicts for the eventual fate of an idea. Thus we now have online journals of memetics and sociobiology, devoted to exploring the possibilities inherent in Dawkins' suggestion in a variety of fairly abstract ways. There are even consultants and think tanks offering their services to those wishing to "inoculate" a population with an idea. We are not quite at the state described in Isaac Asimov's Foundation trilogy, ${ }^{3}$ wherein the mathematical principles governing the ideological and social development of human populations are so well understood that they can be implemented throughout the galaxy to humane ends, but the growing discussions of memetics with their outright mathematical flavor certainly suggest a path in that direction.

Like the concept of "organism" or "gene," the concept of a "meme" is difficult to define or pin down. You are an organism, but so are the cells of your heart. Many small organisms can make up a larger one, just as an idea can be a simple concept or a complex tangle of concepts. Many are the scholarly papers that attempt to sort through this difficulty. As a mathematician, however, I am comfortable with undefined terms and understand the need for them. "Idea," "concept" and "meme" are three such terms. So let us not allow lack of a tight definition to stop us from our pursuit of memetics, and the hopeful consequence of that study: the power to influence cultural beliefs.

A parent knows intuitively that part of their job is to introduce young children to new ideas. Each new concept must be explained in a way that connects it to a child's existing knowledge. Threads are thrown out to anchor a new thought. Children build these connections in their heads in order to allow a new idea to become theirs to play with and think about from that time onward. On a larger scale, cultures do the same thing. The idea of computing, for example, shows how a concept (which in this case leads to an object: the computer) grows by virtue of its connections. Computers do much more than just compute, even though originally that was their purpose. Early computing, as a concept, was tied to the purposes of mathematics and science. When Dick Lehmer built the first paper computer for finding primes, we suspect that word processing was far from his mind. Computing became more fully entrenched in the culture when

\footnotetext{
${ }^{1}$ Bateson, G., Steps to an Ecology of Mind, Chandler, 1972.

${ }^{2}$ Richard Dawkins, The Selfish Gene, second edition, Oxford University Press, 1989.

${ }^{3}$ Asimov, Isaac, Foundation science fiction trilogy, orig. 1942-1953, Doubleday, NY, 1982.
} 
conceptual ties were built to business, writing, keeping records. A computer can help your business earn more money. A computer can assist with correspondence. A computer can deliver the news, let you play chess with someone half a world away, or even buy your groceries. All of these connections were concepts long before they were realities, as anyone who may have grappled with early word processing programs will know. The point is that the idea of computing grew in popularity and importance as its connections to other ideas multiplied. Computing, as a concept, was finding its niche.

\section{An example: The strange case of the Pet Rock}

Perhaps you remember the pet rock. This item was a fad of the seventies, an idea whose time came and went in a historical blink. Somebody had a moment of marketing brilliance and sold an enormous number of rocks decorated with little faces, attached to a piece of paper describing how to care for your new "pet." The concept was humorous and the rock sold for a while. But ultimately, like any fad, pet rocks disappeared both as concept and reality. They deserved this fate.

The pet rock was not a great idea. It had no connection to anything, no utility for anyone. Contrast the pet rock with those equally inanimate pyramids that people purchase still. The pyramid is supposed to increase wealth. It is somehow connected to ancient Egypt, to the Pythagoreans, to mathematics, to occult powers and mysterious religions. People are still buying these, although there is no evidence that it works any better to sleep under one of them than under a pet rock. Somehow the pyramid, by virtue of its connections to other parts of the culture, has managed to survive. The pet rock, that memetic soloist, is pretty much extinct.

In the same way that "pet rock" is a concept built out of the familiar ideas of "pet" and "rock," most ideas come from other ideas by combination or mutation. As in nature, most mutations do not survive. From a Darwinian point of view, culture grows not because people come up with great new ideas but because coming up with new ideas is natural and the irrelevant ones eventually go away. Notice I say "irrelevant," not "bad." You could argue that the idea of totalitarian dictatorship is a bad idea, but you could never argue it is irrelevant. You could, however, make an argument for the irrelevance of the pet rock.

Most ideas are like the pet rock. They come, serve us for a while, and then disappear. Most do not survive. It is hard to document this statement with familiar examples because familiar examples are the survivors, the few that made it. If you want to see the extinct ideas, you must go to a large library. You might look, for example, at everything published in mathematics in Europe during the nineteenth century. Probably only a small proportion of the ideas in that literature are still in play today. Culture abandons most new ideas after time and even our favorite theories may not have a life span beyond us. 
The idea-monger wants to build an idea that stays for a long time and is believed by many people. We want our new idea to be a stable part of the culture at large, the better to create the influence we desire. The example of the pet rock is our first warning: the form the idea is to take matters; its connections to other ideas matter; its chances for survival are small.

\section{An example: The strange case of Quantitative Literacy}

The Quantitative Literacy Design Team assembled by the National Council on Education and the Disciplines produced a "case statement" written by Lynn Steen as the introduction to the collection Mathematics and Democracy: The Case for Quantitative Literacy. ${ }^{4}$ This statement was broad, and connected numeracy to most human activity, from the basic needs of personal finance to the deep use of mathematics to model complex systems. In the eyes of Steen and his colleagues, connections abound between numeracy and all fields of study and human endeavor. In the eyes of the general public, however, this is not the case. Even within the culture of a given university, it is not the case that quantitative literacy is widely believed to have the kind of relevance Steen describes. This is the first problem that must be addressed if quantitative literacy is ever to achieve the same pervasiveness as reading literacy.

To promote numeracy effectively we must simultaneously make it relevant to our students, our university colleagues, and the public at large. Relevant, here, means establishing connections in the minds of individuals between numeracy and other things they already consider truly important. Here is the first big issue. These three populations have very different ideas of what is truly important. For example, a college introducing a new course in quantitative reasoning may need answers to the following four questions:

1. What does this course have to do with my life right now?

2. Will this course improve retention of students in the college track?

3. Will this course improve the retention of students in science?

4. Will students get a better (or any) job as a result?

These four questions come from different populations: the students, the administration, the science division, and those paying for the education (parents and state governments). In asking these questions, each population is telling us what it considers truly important, and secondarily telling us explicitly how to find a niche for quantitative literacy in the culture of that part of the population.

These questions can feel annoying. It is possible to construct slack responses to all of them that "work" as far as providing an answer. Here are some slack answers:

\footnotetext{
${ }^{4}$ Steen, Lynn A., ed, Mathematics and Democracy: The Case for Quantitative Literacy, The National Council on Education and the Disciplines, 2001.
} 
1. What does this course have to do with my life right now? You will not understand how useful this is for a few more years, so we have made it a requirement.

2. Will this course improve retention of students in the college track? It will do no harm because we haven't made it too difficult.

3. Will this course improve the retention of students in science? The science students take a different course.

4. Will students get a better (or any) job as a result? They will get better jobs because they have college degrees. A single course can't matter that much in a job hunt.

It's not that the answers are wrong. But they do not serve the purpose of making numeracy a successful meme, one that is strongly connected to things people think are important. Here are some examples of the kind of answers that might be given for a particular course that are not slack responses:

1. What does this course have to do with my life right now? At the end of this course you will have mastered three skills (listed of course) that you can list on your resume when looking for a summer job.

2. Will this course improve retention of students in the college track? This course includes discussion of the personal finance choices of college age students, with the explicit goal of reducing college exit rates due to financial issues.

3. Will this course improve the retention of students in science? At the end of this course the students will be able to read and understand research literature (of some specific sort).

4. Will students get a better (or any) job as a result? This course requires students to master a (specific) set of skills that (certain specific kinds of) employers are known to desire.

The point is that numeracy is extremely relevant. We are in a position to provide compelling answers to questions of this sort. Numeracy could look a lot more desirable to all constituents than the average university course in any discipline. But those of us promoting the concept must connect it meaningfully to the concerns of society, and do so on many levels. Otherwise it will just become the next educational pet rock. 